\title{
Energy intake and energy expenditure in prepubertal males with asthma
}

\author{
C. Maffeis*, E. Chiocca*, M. Zaffanello*, M. Golinelli*, L. Pinelli*, A.L. Boner*,**
}

\begin{abstract}
Energy intake and energy expenditure in prepubertal males with asthma. C. Maffeis, E. Chiocca, M. Zaffanello, M. Golinelli, L. Pinelli, A.L. Boner. (OERS Journals Ltd 1998.

ABSTRACT: This study aimed to measure energy intake (EI) and total energy expenditure (TEE) of asthmatic males and to validate diet history as a method of estimating their energy requirements.

EI was assessed by dietary history and TEE by the heart-rate monitoring method in a group of asthmatic and nonasthmatic males.

Resting energy expenditure (REE) adjusted for fat-free mass was higher in asthmatic than in nonasthmatic males $\left(5,037\right.$ versus $\left.4,839 \mathrm{~kJ}^{-} \cdot \mathrm{day}^{-1}, \mathrm{p}<0.05\right)$. TEE $(9.3 \pm 1.8$ versus $8.4 \pm 1.4 \mathrm{MJ}^{\prime} \cdot \mathrm{day}^{-1}$, respectively; $\left.\mathrm{p}=\mathrm{Ns}\right)$ and $\mathrm{EI}\left(9.2 \pm 1.5\right.$ versus $8.8 \pm 1.5 \mathrm{MJ} \cdot \mathrm{day}^{-1}$, respectively, $p=N s$ ) were not statistically different in asthmatic and nonasthmatic male. EI was not statistically different from TEE in both groups of males. Asthmatic males showed an acceptable agreement between TEE and EI at the individual level

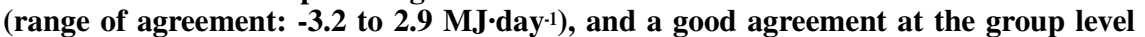
(95\% confidence interval for the bias, -1.1 to $\left.0.8 \mathrm{MJ} \cdot d a y^{-1}\right)$.

Males with mild-to-moderate asthma have a higher metabolic activity per unit fat-free mass than nonasthmatic males. This increased requirement is apparently well compensated by an adequate energy intake. Diet history is a suitable method for estimating energy requirements in males with mild-to-moderate asthma. Eur Respir J 1998; 12: 123-129.
\end{abstract}

*Dept of Paediatrics, University Hospital, Polyclinic, Verona, Italy. **Pio XII Institute, Misurina, Belluno, Italy.

Correspondence: C. Maffeis

Dept of Paediatrics

University of Verona

Polyclinic

37134 Verona

Italy

Fax: 39458200993

Keywords: Asthma children

energy expenditure

energy intake

Received: March 251997

Accepted after revision March 161998
Energy requirements should be assessed by measuring total daily energy expenditure (TEE) [1]. However, because of the difficulty in measuring TEE in free-living conditions, the energy requirements of children are usually estimated from energy intake (EI) [1]. Several studies exploring the relationship between nutrition and health in children have adopted the tacit assumption that the dietary assessment methods used provided valid measures of habitual food intake. At present, scanty data are available on the food intake of asthmatic children [2]; these data have shown that there is no significant difference in the energy intake between asthmatic and nonasthmatic children [2]. Therefore, on the basis of these results, the energy requirements of asthmatic children should be comparable to those of nonasthmatic children. The validity of this conclusion may be questioned because the use of energy intake measurement to assess energy requirements may lead to over- or underestimation, especially in children suffering from chronic disease, such as obesity, cystic fibrosis, chronic obstructive pulmonary disease, cerebral palsy, heart diseases, as well as in asthmatic patients requiring regular treatment to obtain asthma control [3-9]. The simultaneous measurement of EI and TEE in free-living conditions has shown that the measure of energy intake is a valid method of assessing energy requirements in normal children [9]. Two methods have recently been used to measure TEE: the doubly labelled water $\left({ }^{2} \mathrm{H}_{2}{ }^{18} \mathrm{O}\right)$ method [10] and the heart rate (HR) monitoring method [11]. The HR monitoring method allows one to differentiate between energy expenditure due to different activities, sedentary and nonsedentary for instance, during the HR recording interval.

At present no data are available on the energy intake and total daily energy expenditure in prepubertal children suffering from asthma. The purpose of the present study was to measure energy intake and energy expenditure in a group of prepubertal asthmatic males and to validate energy intake assessed by diet history as a method of estimating energy requirements of these subjects.

\section{Material and methods}

\section{Study subjects}

Forth nine prepubertal males participated in the study. Twenty three males had asthma as defined by the American Thoracic Society, and a positive response to a standard questionnaire $[12,13]$. Twenty six healthy males were enrolled as controls. The control children were recruited from the nonobese children who voluntarily enrolled in a study designed to assess the relationship between energy expenditure, physical activity and adiposity, which was in progress at the same time in the Department of Paediatrics of the University of Verona [14]. Obesity was defined as weight $>20 \%$ in excess of ideal body weight for height, age and sex. Medical history, a physical examination, and a negative response to a standard questionnaire allowed us 
to reasonably exclude health problems in the subjects. Asthmatic children were recruited from the paediatric outpatient clinic of the Department of Paediatrics of the University Hospital in Verona, Italy. Following a preliminary study, the subjects were followed on an ambulatory basis for 3 days. Medical history and a physical examination did not reveal any health problems other than asthma. They had mild-to-moderate asthma as established by the current National Heart, Lung and Blood Institute guidelines for severity [13] and by the regular treatment necessary to obtain good asthma control [9]. No child with concomitant eczema was admitted to the study. All the asthmatic patients were on their prophylactic medication with cromoglycate and/or inhaled steroids. Pubertal stage was assessed according to TANNER [15] by evaluating pubic hair and genitalia development. All subjects were graded at Tanner score 1 for sexual maturity. Informed consent was obtained from the subjects and their parents. The protocol was approved by the Ethics Committee of the University Hospital of Verona, Italy.

\section{Physical characteristics}

Anthropometric measurements (weight, height and skinfold thickness) were taken by the same investigator (M. Zaffanello). Height was measured to the nearest $0.5 \mathrm{~cm}$ on a standardized, wall-mounted height board. Weight was determined to the nearest $0.1 \mathrm{~kg}$ on a standard physician's beam scale with the child dressed only in light underwear and without shoes. The body mass index was calculated by dividing weight $(\mathrm{kg})$ by height squared $\left(\mathrm{m}^{2}\right)$.

A Harpenden skinfold calliper (CMS Weighing Equipment Ltd, London, UK) was used to measure skinfolds at the biceps, triceps, supra iliac and sub-scapular sites. Body fat as a percentage of body weight was calculated from the sum of the four skinfolds [16]. Fat-free mass (FFM) was obtained as the difference between body weight and fat mass.

\section{Study design}

The asthmatic children were seen in the outpatient clinic 1 week before energy intake and energy expenditure measurements. Pulmonary function studies were performed by means of a Compact Vitalograph Spirometer (Vitalograph Ltd, Buckingham, UK), and bronchial hyperresponsiveness was evaluated by methacholine challenge [17]. Their current treatment with cromolyn or inhaled steroid was kept unchanged. However, $\beta_{2}$-adrenergic agonists were not allowed during the $24 \mathrm{~h}$ preceding the resting energy expenditure (REE) measurement and the treadmill test performed for the assessment of the relationship between $\mathrm{HR}$ and oxygen consumption $V^{\prime} \mathrm{O}_{2}$. During the days preceding the REE measurement and the treadmill test, the subjects were put on an unrestricted diet; the day before they were requested to avoid any intense physical activity. The subjects arrived by car at the Department of Paediatrics at $07: 30 \mathrm{~h}$ after a $12 \mathrm{~h}$ fast. After $30 \mathrm{~min}$ of rest, during which the subjects were lying down on a hospital bed in a comfortable, temperature-controlled environment $\left(22-24^{\circ} \mathrm{C}\right)$, continuous respiratory exchange measurements were taken by indirect calorimeter to measure REE, as previously described [18]. Then, a light breakfast was served, and approximately $2.5 \mathrm{~h}$ later, a treadmill test (intermittent incremental) was performed to evaluate energy expenditure [19]. Peak expiratory flow rate (PEFR) was measured before, during and after the exercise test in order to check for any bronchial obstruction.

\section{Energy intake}

Typical weekly meal and snack intakes were obtained from an interview with the mothers and subjects [20]. Information regarding portion size, food preparation and place of consumption was also recorded. A dietician (M. Golinelli) consulted with the family to obtain a careful record of foods and portions consumed that had not been mentioned. As an aid to determining the amount of food consumed, pictures of different food items were presented, and cups, glasses, spoons and food shapes of different portion sizes were used. Food intake at school was assessed by reviewing a typical week's menu with the children and asking them to indicate which and how much of these meals that they usually ate. Meals, snacks, portion sizes and frequency of eating were recorded on a standard form. All interviews were conducted by the same dietician. Food energy values were calculated from tables of food composition set by the Italian Institute of Nutrition [21] using a computerized database and analysis programme (Contrali, Dietosystem, Milan, Italy).

\section{Energy expenditure calculation from heart rate}

The relationship between $\mathrm{HR}$ and $V^{\prime} \mathrm{O}_{2}$ was established for each subject following the treadmill test. To determine the individual $\mathrm{HR}-V^{\prime} \mathrm{O}_{2}$ regression line, a physical exercise test was performed, during which $V^{\prime} \mathrm{O}_{2}$ and $\mathrm{HR}$ were simultaneously measured under standardized conditions, as previously described [19]. Briefly, $V^{\prime} \mathrm{O}_{2}$ and carbon dioxide production $\left(V^{\prime} \mathrm{CO}_{2}\right)$ were measured with a standard open circuit method. Sedentary values of $V^{\prime} \mathrm{O}_{2}$ and $\mathrm{HR}$ were obtained while the subject was in a lying, sitting, and standing position. The sedentary energy expenditure was defined as the mean of the energy expenditure value for the three resting activities, as calculated from $V^{\prime} \mathrm{O}_{2}$ values.

Five calibration points for the nonresting activities were made during walking and running on the treadmill (PV Rolling belt, Beta, Milan, Italy) at a speed of 2, 3, 5, 6, 7 $\mathrm{km} \cdot \mathrm{h}^{-1}$ respectively. Measurements of $V^{\prime} \mathrm{O}_{2}$ and $\mathrm{HR}$ were made during the last $3 \mathrm{~min}$ of each walking or running period, thus in a steady-state condition. The energy expenditure was calculated from $V^{\prime} \mathrm{O}_{2}$ by means of the simplified Weir formula, which assigns $20.5 \mathrm{~kJ} \cdot \mathrm{L}^{-1}$ of $\mathrm{O}_{2}$ consumed [22].

A critical heart rate, the FLEX HR, was determined for each child as previously described [19]. FLEX HR is an individually predetermined HR cut-off point that can be used to discriminate between resting and exercise HR in free-living conditions. It was calculated as the arithmetic mean between the highest HR obtained for the resting activities (lying, sitting and standing positions) and the lowest HR obtained during the lightest imposed exercise. Above the FLEX value, the calibration curve used to estimate energy expenditure corresponded to that of the active period, and below the FLEX, the sedentary energy 
expenditure value was used to determine the energy expenditure during inactivity.

The TEE was calculated by summing the sleeping energy expenditure (SEE), sedentary energy expenditure and activity energy expenditure. Sleeping energy expenditure was assessed by multiplying the sleeping time ( $\mathrm{min}$ ) by REE (kJ.min $\left.{ }^{-1}\right)$. Sedentary energy expenditure was calculated by multiplying the nonsleeping time (daily time under FLEX HR) by SEE. Nonsedentary energy expenditure was calculated by determining $V^{\prime} \mathrm{O}_{2}$ for each HR greater than the FLEX HR from each individual calibration line.

\section{Heart rate monitoring}

HR was recorded continuously for 3-4 days (usually including two weekdays and one weekend day) during normal daily activities under free-living conditions, as previously described [19]. Briefly, the HR transmitter was attached to the chest with an elastic band. Parents were instructed to attach the band with the electrodes and the HR transmitter to the chest and to turn the recorder on the wrist on and off. The pulse was recorded at 1 min intervals continuously up to $16 \mathrm{~h}$. Information was retrieved daily at the subject's home by the same operator (M. Zaffanello) via an interface unit and a personal computer. HR monitoring started in the morning immediately after waking and continued until bedtime. The sleeping time was assessed by recording the time between going to bed and waking up, recorded by the subjects and/or their parents in a notebook. Whenever the HR daily recording was incomplete (in Y $15 \%$ of cases), the subjects were asked to repeat the monitoring for an additional day. At the end of the study, complete 3 day HR measurements were obtained from each child.

TEE measurement was performed in 16 asthmatic males. However, only data for 15 subjects are reported because one subject developed eczema on the skin under the HR transmitter and so had to interrupt the HR recording and was eliminated from the study.

\section{Analysis}

The results are expressed as means and standard deviation. The Mann-Whitney test was used to compare anthropometric characteristics, REE, TEE, and EI in asthmatic and nonasthmatic males. ANCOVA, using FFM as the covariate, was used to calculate REE adjusted for FFM [19]. Friedman's test was performed to compare reported EI and TEE calculated from HR monitoring. The agreement between estimates of TEE and EI was assessed using the method of BLAND and AltMan [23]. Correlations between REE and respiratory function variables were determined using Pearson's product-moment correlation.

\section{Results}

\section{Physical and respiratory characteristics}

Physical characteristics of asthmatic and nonasthmatic children are shown in table 1 . The anthropometric values were not significantly different between the two groups of subjects. The data on pulmonary function and results of
Table 1. - Physical characteristics of asthmatic and nonasthmatic subjects

\begin{tabular}{lccc}
\hline & $\begin{array}{c}\text { Asthmatic } \\
(\mathrm{n}=23)\end{array}$ & $\begin{array}{c}\text { Nonasthmatic } \\
(\mathrm{n}=26)\end{array}$ & p-value \\
\hline Age yrs & $9.2 \pm 0.9$ & $9.2 \pm 1.1$ & Ns \\
Weight kg & $32.6 \pm 5.4$ & $33.7 \pm 6.6$ & Ns \\
Height cm & $136 \pm 6$ & $135 \pm 6$ & Ns \\
BMI kg.m ${ }^{-2}$ & $17.7 \pm 3.6$ & $18.7 \pm 3.4$ & Ns \\
FM \% & $18.2 \pm 4.6$ & $20.6 \pm 8.7$ & Ns \\
FM kg & $6.1 \pm 2.3$ & $7.4 \pm 4.4$ & Ns \\
FFM kg & $26.5 \pm 3.4$ & $26.3 \pm 3.1$ & s \\
\hline
\end{tabular}

Data are shown as mean \pm SD. BMI: body mass index; FM: fat mass. FFM: fat-free mass. ss: nonsignificant.

Table 2. - Pulmonary function parameters of asthmatic subjects

\begin{tabular}{lc}
\hline FEV $1 \%$ pred & $86 \pm 7$ \\
FEV 1/VC & $0.79 \pm 0.08$ \\
PEF \% pred & $83 \pm 18$ \\
FEF25-75\% \% pred & $69 \pm 15$ \\
PC20 methacholine & $1.6 \pm 1.3$
\end{tabular}

Data are shown as mean \pm SD and expressed as a percentage of the value predicted for patient height and age, and the provocative dose of methacholine causing a $20 \%$ fall in forced expira-

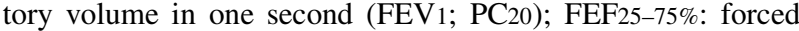
mid-expiratory flow. PEF: peak expiratory flow. VC: vital capacity.

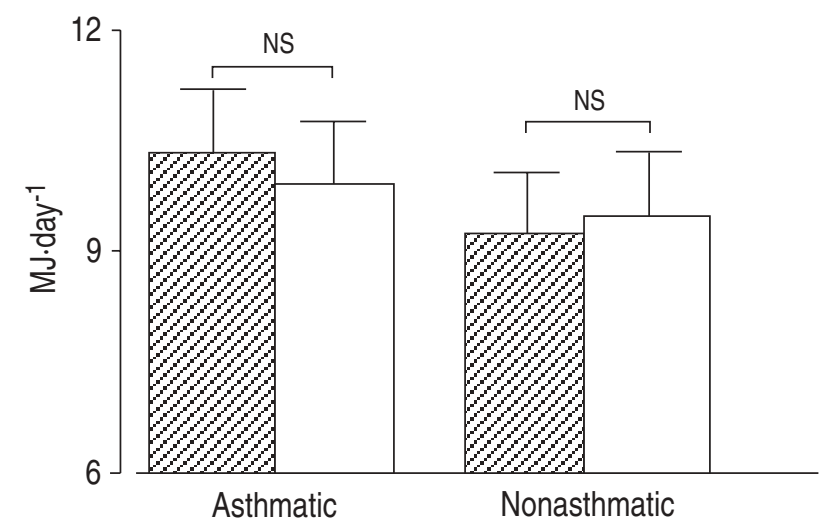

Fig. 1. - Energy intake ( $Z$ ) assessed by diet history and total energy expenditure ( $\square$ ) measured by heart rate monitoring in asthmatic and nonasthmatic children. Data are shown as mean \pm SD.

methacholine challenge in asthmatic subjects are shown in table 2. Only four patients in our study population required occasional treatment with $\beta_{2}$-agonists more than once a week.

\section{Energy intake}

Mean energy intake assessed by diet history was not statistically different between the asthmatic and nonasthmatic subjects $\left(9.17 \pm 1.54\right.$ versus $8.83 \pm 1.50 \mathrm{MJ} \cdot$ day $^{-1}(\mathrm{p}=$ NS)). In both groups, EI was not statistically different to TEE (fig. 1). In the asthmatic subjects, the level of agreement between the two measurements was acceptable at the individual level: mean difference $-0.1 \mathrm{MJ} \cdot \mathrm{day}^{-1}$ (range of agreement (mean difference $\pm 1.96 \mathrm{sD}$ ) -3.2 to $2.9 \mathrm{MJ}$. day $^{-1}$ ) (fig. 2), and good agreement at the group level (95\% 

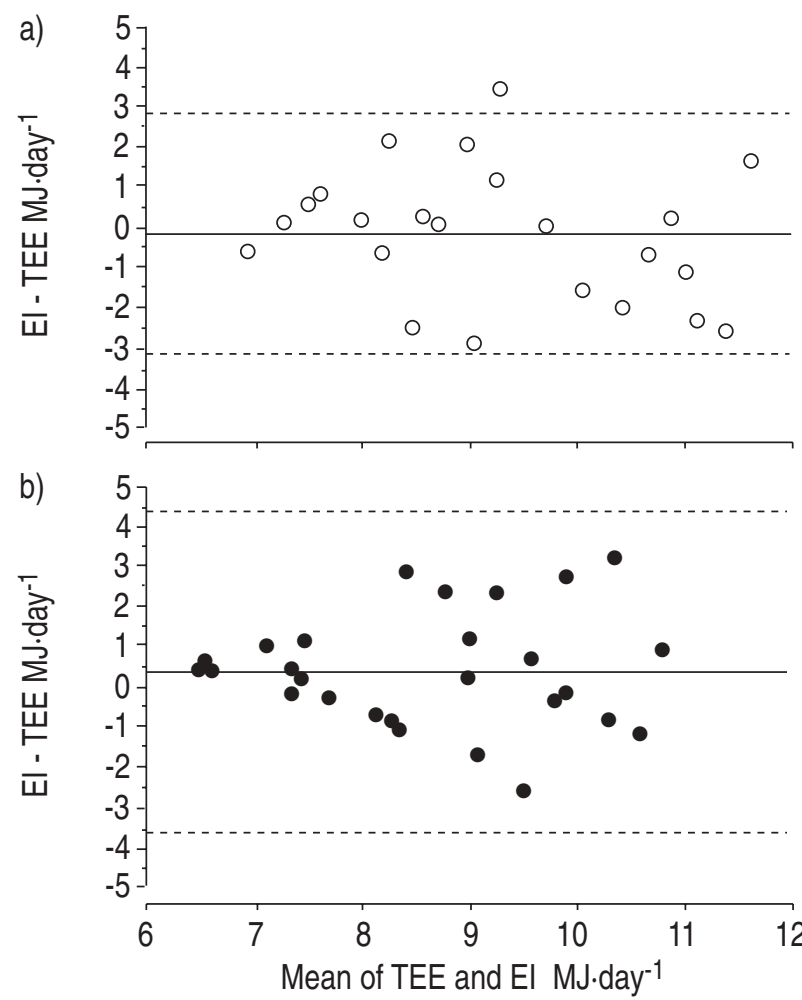

Fig. 2. - Individual differences between energy intake (EI) and total energy expenditure (TEE) plotted against the mean of the EI and TEE measurements of: a) asthmatic children and b) nonasthmatic children. - : mean; --------: mean \pm 1.96 SD.

Table 3. - Postabsorptive resting energy expenditure (REE) in asthmatic and nonasthmatic subjects

\begin{tabular}{lccc}
\hline & $\begin{array}{c}\text { Asthmatic } \\
(\mathrm{n}=23)\end{array}$ & $\begin{array}{c}\text { Nonasthmatic } \\
(\mathrm{n}=26)\end{array}$ & $\mathrm{p}$ \\
\hline REE kJ·day-1 & $5045 \pm 447$ & $4832 \pm 381$ & $\mathrm{NS}$ \\
$\begin{array}{l}\text { REE adjusted for FFM } \\
\mathrm{kJ} \cdot \text { day }^{-1}\end{array}$ & 5037 & 4839 & $<0.05$ \\
RQ & $0.88 \pm 0.04$ & $0.88 \pm 0.03$ & $\mathrm{~N}$ \\
\hline
\end{tabular}

Values are shown as mean \pm SD and are expressed as an absolute value $\left(\mu \mathrm{g} \cdot \mathrm{day}^{-1}\right)$ and adjusted for fat-free mass (FFM) by ANCOVA, using FFM as a covariate and respiratory quotient (RQ).

confidence interval (CI) for the bias, -1.1 to $\left.0.8 \mathrm{MJ} \cdot \mathrm{day}^{-1}\right)$. In the nonasthmatic subjects, the level of agreement between the two measurements was acceptable at the individual level: mean difference $0.3 \mathrm{MJ} \cdot \mathrm{day}^{-1}$ (range of agreement,

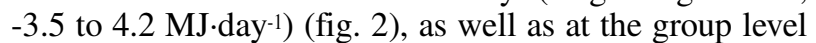

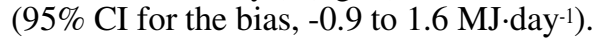

Nutrient intake was not statistically different between the two groups of children: protein \%: $12.8 \pm 3.3$ versus $14.8 \pm 2.8$ ( $\mathrm{p}=\mathrm{Ns})$, fat \%: $34.0 \pm 5.6$ versus $35.4 \pm 6.2(\mathrm{p}=\mathrm{Ns})$; carbohydrate \%: $54.0 \pm 9.2$ versus $50.3 \pm 7.6(\mathrm{p}=\mathrm{Ns})$, for asthmatic versus nonasthmatic subjects, respectively.

\section{Energy expenditure}

Postabsorptive resting energy expenditure. Expressed as an absolute value, REE was not statistically different between the two groups of subjects (table 3 ). REE adjusted for FFM, i.e. the metabolic active tissue, using FFM as the covariate, was higher in the asthmatic than in the nonasthmatic children $(\mathrm{p}<0.05)$.

In the asthmatic group, the relationship between REE adjusted for FFM and forced expiratory volume in one second (FEV1) (\% predicted), FEV1/vital capacity (VC), peak expiratory flow (PEF; \% pred), and forced mid-expiratory flow (FEF25-75\%; \% pred) was not significant (table 4 ). The provocative concentration causing a $20 \%$ fall in FEV1 (PC20) showed a negative, significant correlation with REE adjusted for FFM $(r=-0.32 ; \mathrm{p}<0.05)$.

Total daily energy expenditure. Resting HR, FLEX HR, daytime $\mathrm{HR}$ and peak $V^{\prime} \mathrm{O}_{2}$ were not significantly different between the two groups (table 5). HR at 50\% peak $V^{\prime} \mathrm{O}_{2}$ was significantly lower $(\mathrm{p}<0.001)$ in the group of subjects with asthma than in the control group, whereas HR at $70 \%$ peak $V^{\prime} \mathrm{O}_{2}$ was not statistically different in the two groups. The time spent on moderate or vigorous activity, (for example the time spent with an HR ranging from $50-70 \%$ of peak $V^{\prime} \mathrm{O}_{2}$ and an $\mathrm{HR}>70 \%$ peak $V^{\prime} \mathrm{O}_{2}$, respectively), was higher $(\mathrm{p}<0.02)$ in males with asthma than in the control group.

TEE expressed as an absolute value was not significantly different between subjects with or without asthma

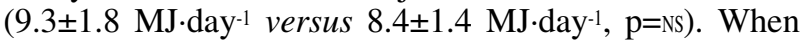
expressed per $\mathrm{kg}$ of FFM (352 \pm 43 versus $320 \pm 39 \mathrm{~kJ} \cdot \mathrm{kg}$ FFM $^{-1} \cdot$ day $\left.^{-1}, \mathrm{p}<0.01\right)$ or per $\mathrm{kg}$ of body weight $(286 \pm 41$ versus $250 \pm 33 \mathrm{~kJ} \cdot \mathrm{kg}^{-1} \cdot \mathrm{day}^{-1}, \mathrm{p}<0.01$ ), TEE was significantly higher in subjects with asthma than in nonasthmatic subjects.

The energy expenditure during physical activity (including thermogenesis), for example TEE-REE, expressed as an absolute value, was higher in the asthmatic than in the nonasthmatic group $\left(4.5 \pm 1.6\right.$ versus $3.6 \pm 1.1 \mathrm{MJ} \cdot$ day $^{-1}, \mathrm{p}<$ $0.05)$. Expressed per $\mathrm{kg}$ of FFM (165 \pm 46 versus $144 \pm 39$ $\left.\mathrm{kJ} \cdot \mathrm{kgFFM}^{-1} \cdot \mathrm{day}^{-1}, \mathrm{p}=\mathrm{NS}\right)$ or per $\mathrm{kg}$ of body weight $(138 \pm 38$ versus $115 \pm 30 \mathrm{~kJ} \cdot \mathrm{kg}^{-1} \cdot \mathrm{day}^{-1}, \mathrm{p}=\mathrm{Ns}$ ), it was not statistically different between the asthmatic or nonasthmatic subjects.

The activity index, TEE/REE ratio, was not statistically different between the two groups (asthmatic versus nonasthmatic: $1.89 \pm 028$ versus $1.78 \pm 0.22, \mathrm{p}=\mathrm{Ns}$ ).

The subjects with asthma spent significantly more time sleeping than the nonasthmatic subjects did (fig. 3); therefore, the energy expenditure for sleeping was significantly higher in the former (fig. 4). The time devoted to sedentary activities (time spent with HR below FLEX HR) and to nonsedentary activities (time spent with HR above FLEX HR) was not statistically different in the two groups of children. The energy expenditure for resting and nonresting activities was not statistically different between the two groups.

Table 4. - Relationship between resting energy expenditure (REE) adjusted for fat-free mass and respiratory variables in asthmatic subjects

\begin{tabular}{lrc}
\hline & $\mathrm{r}$ & $\mathrm{p}$ \\
\hline REE adjusted for FFM versus: & & \\
FEV1 \% pred & -0.01 & Ns \\
FEV1/VC & -0.02 & Ns \\
PEFbasal \% pred & -0.03 & Ns \\
FEF25-75\% \% pred & 0.05 & NS \\
PC20 methacholine & -0.32 & $<0.05$ \\
\hline
\end{tabular}

PEFbasal: basal peak expiratory flow. For definitions see legends to tables 1 and 2 . 
Table 5. - Resting heart rate $(\mathrm{HR})$, FLEX HR, daytime HR, peak oxygen uptake $\left(V^{\prime} \mathrm{O}_{2}\right), \mathrm{HR}$ interval and time at moderate and vigorous activity in asthmatic and nonasthmatic males

\begin{tabular}{|c|c|c|c|}
\hline & $\begin{array}{c}\text { Asthmatic } \\
(\mathrm{n}=15)\end{array}$ & $\begin{array}{c}\text { Nonasthmatic } \\
(n=26)\end{array}$ & $\mathrm{p}$ \\
\hline Resting HR beats $\cdot \mathrm{min}^{-1}$ & $83 \pm 7$ & $85 \pm 10$ & NS \\
\hline FLEX HR beats $\cdot \mathrm{min}^{-1}$ & $92 \pm 10$ & $92 \pm 6$ & NS \\
\hline Daytime HR beats. $\min ^{-1}$ & $110 \pm 7$ & $105 \pm 7$ & NS \\
\hline Peak $V^{\prime} \mathrm{O}_{2} \mathrm{~L} \cdot \mathrm{min}^{-1}$ & $1.27 \pm 0.2$ & $1.39 \pm 0.23$ & NS \\
\hline $\mathrm{HR}$ at $50 \%$ peak $V^{\prime} \mathrm{O}_{2}$ beats. $\min ^{-1}$ & $120 \pm 6$ & $132 \pm 7$ & $<0.01$ \\
\hline $\mathrm{HR}$ at $70 \%$ peak $V^{\prime} \mathrm{O}_{2}$ beats. $\mathrm{min}^{-1}$ & $140 \pm 35$ & $154 \pm 9$ & NS \\
\hline \multicolumn{4}{|l|}{ Time spent on: } \\
\hline moderate activity $\min \cdot$ day $^{-1} *$ & $93 \pm 51$ & $53 \pm 32$ & $<0.02$ \\
\hline vigorous activity $\mathrm{min} \cdot \mathrm{day}^{-1} * *$ & $37 \pm 26$ & $19 \pm 13$ & $<0.02$ \\
\hline
\end{tabular}

Values are shown as mean \pm SD. *: time spent at $\mathrm{HR}$ greater than $\mathrm{HR}$ at $50 \%$ peak $V^{\prime} \mathrm{O}_{2}$ and lower than $\mathrm{HR}$ at $70 \%$ peak $V^{\prime} \mathrm{O}_{2} . * *$ : time spent at $\mathrm{HR}$ greater than $\mathrm{HR}$ at $70 \%$ peak $V^{\prime} \mathrm{O}_{2}$. FLEX HR: HR cut-off point determined from free-living and exercise values (see Methods).

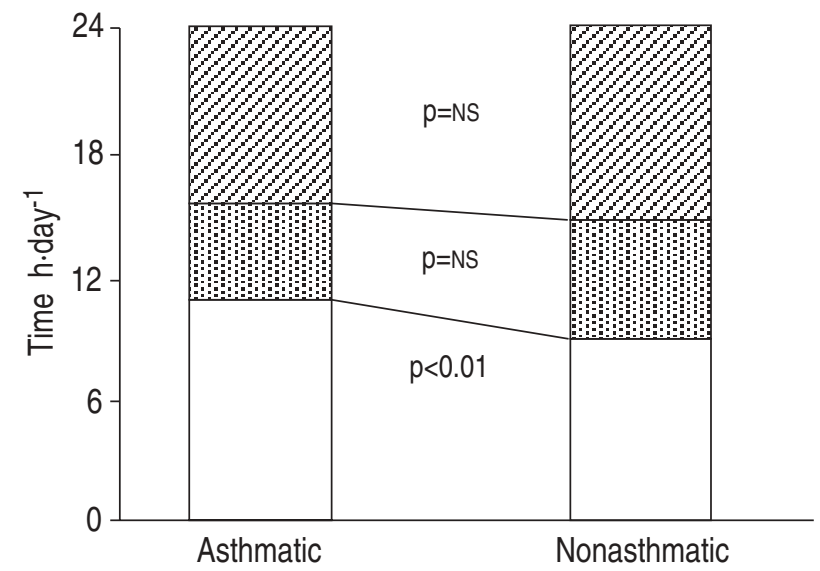

Fig. 3. - Time spent on different activities ( $\square$ : sleeping; ::: : sedentary activities (below FLEX heart rate); 20 : nonsedentary activities (above FLEX heart rate)) in children with and without asthma.

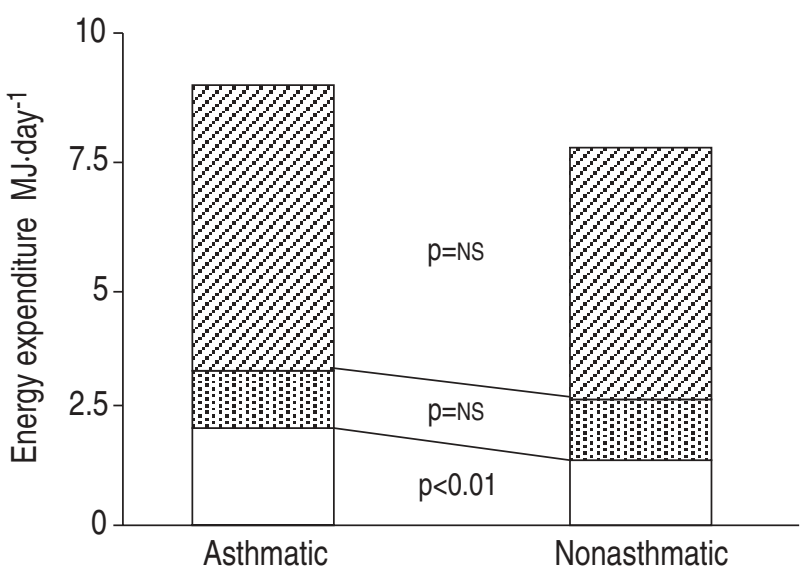

Fig. 4. - Energy spent during different activities ( $\square$ : sleeping; : : : sedentary activities (below FLEX heart rate); $叉 2$ : nonsedentary activities (above FLEX heart rate)) in children with and without asthma.

\section{Discussion}

Dietary recommendations are based on energy requirements, i.e. TEE [1]. Subjects suffering from chronic diseases such as obesity, cystic fibrosis, chronic obstructive pulmonary disease, cerebral palsy, heart diseases, etc. may have different energy requirements than those of the age- and sex-matched healthy population [3-7]. Asthma is the most common respiratory disease in children, with a mean prevalence of Y10\% in Italy [24]. This is the first study to investigate TEE in asthmatic children. The results show that the TEE of males suffering from mild-to-moderate asthma are not significantly different from those of nonasthmatic males. However, males with mild-to-moderate asthma, receiving conventional inhaled treatment, spend more energy per unit FFM than nonasthmatic males. This is mainly due to REE, the main component of TEE, since energy expenditure during activity (+ thermogenesis), i.e. TEE - REE, expressed per kg of FFM, is not significantly different in the two groups of subjects. The mean value of REE adjusted for FFM was significantly higher in the asthmatic subjects, and is in agreement with the data reported by Zeituin et al. [2].

Several factors might contribute to explaining the higher metabolic activity of FFM in males with asthma. Drugs, in particular $\beta_{2}$-adrenergic agonists, affect energy expenditure by means of their multisystemic actions. They may potentially play a role in increasing REE in asthmatic children who use these medications, although a short-duration (60-90 min after administration) thermogenic effect of these drugs has been demonstrated [25]. To avoid this effect, $\beta_{2}$-adrenergic agonists were not allowed during the $24 \mathrm{~h}$ preceding the measurement of the postabsorptive metabolic rate and the treadmill test for the assessment of the $\mathrm{HR} / V^{\prime} \mathrm{O}_{2}$ relationship. Another contributing factor could be the inflammatory response associated with asthma. The evidence of bronchial hyperresponsiveness in our children, as shown by the positive response to the methacholine challenge, indicates bronchial inflammation. In fact, we found a negative correlation between methacholine PC20 and REE adjusted for FFM. In this sample of subjects, the inflammatory level in the airways was not specifically investigated with bronchial washing, biopsy or evaluation of cells in induced sputum. Eczema, which is another inflammatory process that potentially may contribute to increasing energy expenditure [2], was not found in any subject. Finally, the energy cost of breathing might potentially affect REE in asthmatic children, as suggested by the inverse relationship between $\mathrm{PC}_{20}$ methacholine and REE adjusted for FFM. However, the actual cost of breathing in resting conditions is low: $\mathrm{Y}^{3} \%$ of total $V^{\prime} \mathrm{O}_{2}$ in normal subjects and $Y$ Y $8 \%$ in patients with severe chronic airflow limitation (FEV1 Y41\%; FEF25-75\% Ý12\%); therefore, its influence on REE should be reasonably 
modest in children with mild or moderate asthma [26]. No direct measurements of the oxygen cost of breathing were taken in this study to verify this hypothesis.

The subjects with asthma showed patterns of activity and a mean level of activity that were not significantly different from those of the control group. In fact, the energy spent above the postabsorptive metabolic rate (TEE $\mathrm{REE}$ ), including the energy expenditure devoted to physical activity, postprandial thermogenesis and the metabolic cost of growth (assumed to be negligible and within our error of measurement in $9 \mathrm{yr}$ old children), was not statistically different between the two groups, when it was expressed per unit of FFM or body weight. In addition, the time and energy expenditure devoted to sedentary and nonsedentary activities were not significantly different in the two groups of subjects. These data are confirmed by the TEE/REE ratio, a gross index of activity, which was not significantly different in the two groups.

Some of the results of this study (HR at $50 \%$ peak $V^{\prime} \mathrm{O}_{2}$, sleeping time, time spent in moderate and vigorous activity) suggest that asthmatic subjects may be more physically fit than nonasthmatic subjects. This could be the result of the encouragement to perform physical activity given to the asthmatic children who are in a good respiratory condition. In fact, asthmatic subjects seem to be slightly (although not significantly) more physically active than nonasthmatic subjects. This result is supported by the finding that EI assessed on the basis of the diet history method was not significantly different from TEE and from the Recommended Dietary Allowances for age [27] in both groups. In other words, the food intake of the asthmatic subjects appeared to be adequate for their mean daily energy requirements, as suggested by the results of the Bland and Altman [23] analysis, and offered an acceptable estimation of the requirements themselves. The measurement of habitual food intake is one of the most challenging aspects of nutrition research in both adults and children. In each of the available techniques, the approach is at the discretion of the interviewer. One additional limitation in children is the reliance of a third person (mother, teacher, grandmother, etc.) to remember the intake of the child. Many investigators feel that the diet history method to measure EI in children is more suitable and more valid than the weighed dietary record in a study performed in a group of 3-18 yr old healthy children, using the doublelabelled water method to assess TEE [9]. The diet history method is based on the assumption that children are in energy balance; this is reasonably true in the short-tomedium term. However, this may not be true in subjects who are in worse clinical conditions. The diet history method is subjective and measures only memory and perception of the usual diet. It is vulnerable to exaggeration of good food and under-reporting of bad foods, especially in children, and to the accuracy of the parents reporting food intake of their children. Recall bias, motivation level, inability to correctly appraise serving sizes, etc. might affect the validity of the method [28]. The experience of the interviewer may also affect the accuracy of the method as well as the obesity of the child or of their parents [3, 18]. In spite of these considerations, the dietary history method was found to be an acceptable method of estimating EI and energy requirements in our asthmatic children, at least at the group level.
In conclusion, males with mild-to-moderate asthma have a higher metabolic activity per unit fat-free mass than nonasthmatic males. This increased requirement is apparently well compensated for by an adequate energy intake. No evidence of a negative energy balance in children with mild-to-moderate asthma was found. Diet history may be used to estimate energy requirements in children with mild-to-moderate asthma.

\section{References}

1. World Health Organisation. Energy and protein requirements: report of a joint $\mathrm{FAO} / \mathrm{WHO} / \mathrm{UNU}$ expert consultation. Geneva: World Health Organisation 1985, p. 35.

2. Zeitlin RS, Bond S, Wootton S, Gregson RK, Radford M. Increased resting energy expenditure in childhood asthma: does this contribute towards growth failure? Arch Dis Child 1992; 67: 1366-1369.

3. Bandini LG, Schoeller DA, Cyr HN, Dietz WH. Validity of reported energy intake in obese and non-obese adolescents. Am J Clin Nutr 1990; 52: 421-425.

4. Vaisman N, Pencharz PB, Corey M, Canny GJ, Hahn E. Energy expenditure of patients with cystic fibrosis. J Pediatr 1987; 111: 496-500.

5. Schols AMWJ, Fredrix EWHM, Soeters PB, Westerterp KR, Wouters EFM. Resting energy expenditure in patients with obstructive pulmonary disease. Am J Clin Nutr 1991; 54: 983-987.

6. Bandini LG, Shoeller DA, Fukagawa NK, Wykes LG, Dietz WH. Body composition and energy expenditure in adolescents with cerebral palsy or myelodysplasia. Pediatr Res 1991; 29: 70-77.

7. Barton JS, Hindmarsh PC, Scrimgeour CM, Rennie MJ, Preece MA. Energy expenditure in congenital heart disease. Arch Dis Child 1994; 70: 5-9.

8. Cockcroft DW, Swystun VA. Asthma control versus asthma severity. J Allergy Clin Immunol 1996; 98: 1016-1018.

9. Livingstone MB, Prentice AM, Coward AW, et al. Validation of estimates of energy intake by weighed dietary record and diet history in children and adolescents. Am J Clin Nutr 1992; 56: 29-35.

10. Schoeller DA, van Santen E. Measurement of energy expenditure in humans by doubly labelled water method. $J$ Appl Physiol 1982; 53: 955-959.

11. Bradfield R. A technique for determination of usual daily energy expenditure in the field. Am J Clin Nutr 1971; 24: $1148-1154$.

12. American Thoracic Society Committee on Diagnostic Standards. Definition and classification of chronic bronchitis, asthma and pulmonary emphysema. Am Rev Respir Dis 1962; 85: 762.

13. National Asthma Education Program Expert Panel Report. Guidelines for the Diagnosis and Management of Asthma Bethesda, MD, National Heart, Lung, and Blood Institute, US Department of Health and Human Services Publication No. NIH 1991; 91-3042.

14. Maffeis C, Zaffanello M, Schutz Y. Relationship between physical inactivity and adiposity in prepubertal boys. $J$ Pediatr 1997; 151: 288-294.

15. Tanner JM. Growth at Adolescence, 2nd Edn, Oxford, Blackwell, 1962.

16. Deurenberg P, Pieters JJL, Haustvast JGA. The assessment of the body fat percentage by skinfold thickness measurements in childhood and young adolescence. $\mathrm{Br} J$ Nutr 1990; 63: 293-303.

17. Peroni DG, Boner AL, Vallone G, Antolini I, Warner JO. Effective allergen avoidance at high altitude reduces 
allergen-induced bronchial hyperresponsiveness. Am J Respir Crit Care Med 1994; 149: 1442-1446.

18. Maffeis C, Schutz Y, Zaffanello M, Piccoli R, Pinelli L. Elevated energy expenditure and reduced energy intake in obese prepubertal children: paradox of poor dietary reliability in obesity? J Pediatr 1994; 124: 348-354.

19. Maffeis C, Schutz Y, Pinelli L. Effect of weight loss on resting energy expenditure in obese prepubertal children. Int J Obes 1992; 16 (1): 41-47.

20. van Steveren WA, de Boer JD, Burema J. Validity and reproducibility of a dietary history method estimating the usual food intake during one month. Am J Clin Nutr 1985; 42: 554-559.

21. Italian Society of Human Nutrition. National daily recommended intakes of nutrients 1986-87. Milan, Litho Delta, 1988.

22. Weir JB. New method for calculating metabolic rate with special references to metabolism. J Physiol 1949; 109: 1-9.
23. Bland JM, Altman DG. Statistical methods for assessing agreement between two methods of clinical experiment. Lancet 1986; 1: 307-310.

24. Peroni DG, Piacentini GL, Zizzo MG, Boner AL. Prevalence of wheezing, rhinitis and eczema in 6-7-year-old children resident in North-eastem Italy. Eur Respir J 1996; 9: 233 (abst).

25. Vaisman N, Levy LD, Pencharz PB, et al. Effect of salbutamol on resting energy expenditure in patient with cystic fibrosis. J Pediatr 1987; 111: 137-139.

26. Katsardis CV, Desmond KJ, Coates AL. Measuring the oxygen cost of breathing in normal adults and patients with cystic fibrosis. Respir Physiol 1986; 65: 257-266.

27. Recommended dietary allowances. 10th Edn, Washington, DC, National Academic Press, 1989; pp. 24-38.

28. Baranowski T, Spragne D, Baranowski JH, Harrison JA. Accuracy of maternal dietary recall for preschool children. J Am Diet Assoc 1991; 91: 669-674. 